\title{
Staphylococcal Septic Arthritis
}

National Cancer Institute

\section{Source}

National Cancer Institute. Staphylococcal Septic Arthritis. NCI Thesaurus. Code C27306.

Arthritis due to staphylococcal sepsis. 